'Sección de Nefrología, Departamento de Medicina, Hospital Clínico Universidad de Chile. Santiago, Chile. ${ }^{2}$ Centro de Investigación Clínica Avanzada, Hospital Clínico Universidad de Chile. Santiago, Chile. 3Centro de Pacientes Críticos, Clínica Las Condes. Santiago, Chile. ${ }^{4}$ Sección de Reumatología, Departamento de Medicina, Hospital Clínico Universidad de Chile. Santiago, Chile.

${ }^{5}$ Sección de Medicina Interna, Departamento de Medicina, Hospital Clínico Universidad de Chile. Santiago, Chile.

${ }^{6}$ Interna de Medicina, Facultad de Medicina Universidad de Chile. Santiago, Chile.

Financiamiento: FONDECYT de Iniciación N¹1171141 (Luis Toro). Los autores declaran no tener conflictos de interés.

Recibido el 31 de diciembre de 2020, aceptado el 24 de mayo de 2021

Correspondencia a: Dr. Luis Toro Cabrera, MD PhD FACP. Servicio de Nefrología, Departamento de Medicina, Hospital Clínico Universidad de Chile. Santiago, Chile. Eduardo Lorca Tobar 999, Independencia. Santiago, Chile. Itoro@med.uchile.cl

\section{Rabdomiólisis como presentación inicial de COVID-19. Caso Clínico}

\author{
LUIS TORO ${ }^{1,2,3}$, PEDRO ZAMORANO $^{4}$, ALONDRA FRÍAS $^{1}$, \\ ALFREDO PARRA-LUCARES ${ }^{5}$, MARÍA FERNANDA SILVA ${ }^{6}$, \\ PAULA ALMEIDA ${ }^{6}$, MARÍA FRANCISCA BOZÁN ${ }^{4}$, \\ MARÍA EUGENIA SANHUEZA ${ }^{1}$, RUBÉN TORRES ${ }^{1}$
}

\section{Rhabdomyolysis as the presentation form of COVID-19 infection. Report of one case}

COVID-19 infection causes a systemic inflammatory response, which mainly presents as a febrile syndrome with respiratory involvement. We report a 37-year-old male who consulted for myalgia, nausea and epigastric pain lasting three days. On admission, he had crepitations at the lung bases. The initial laboratory showed a creatine kinase of 62,768 U/L, a LDH of 1,110 IU/L, a creatinine a $2.1 \mathrm{mg} / \mathrm{dL}$, an aspartate aminotransferase of 1,347 IU/L, a D-dimer of 1,140 ng/mL, a ferritin of $1,201 \mathrm{ng} / \mathrm{mL}$ and a lymphocyte count of 810 cells $/ \mathrm{mm}^{3}$. The chest CT scan was compatible with multifocal pneumonia, suggesting a COVID-19 infection. COVID-19 PCR was positive. The patient was managed with hydration, sodium bicarbonate, ceftriaxone, and azithromycin, with a good clinical response.

(Rev Med Chile 2021; 149: 796-802)

Key words: Acute Kidney Injury; COVID-19; Renal Insufficiency, Chronic; Rhabdomyolysis; SARS-CoV-2.
L a infección por COVID-19 provoca una respuesta inflamatoria sistémica. Su forma más común de presentación en $80 \%$ de los casos es un síndrome febril con moderado compromiso respiratorio, y con falla respiratoria aguda severa en $5 \%$ de los $\operatorname{casos}^{1,2}$.

A continuación, se muestra un caso de rabdomiólisis como el inicio de la infección por COVID-19. Nuestro objetivo es describir y caracterizar la rabdomiolisis como una manifestación poco común de COVID-19, con el fin de alertar a los médicos de una presentación potencialmente letal. El paciente entregó consentimiento informado para la presentación del caso, quien solicitó mantener confidencialidad de su identidad.

\section{Caso clínico}

Hombre de 37 años, sin patologías conocidas ni antecedentes familiares. Su actividad laboral diaria requería un alto nivel de esfuerzo físico, que había aumentado durante la última semana. Acudió al Servicio de Urgencias por mialgia proximal asociada a náuseas y epigastralgia con irradiación a la espalda, de 3 días de evolución. No tenía fiebre, síntomas respiratorios, debilidad muscular, dermatosis, diarrea ni cambios en las características de la orina. El paciente no tomaba medicamentos, alcohol ni drogas lícitas o ilícitas; tampoco había tenido antecedentes de trauma, ejercicio físico intenso o lesiones musculares recientes ni evidencia de infecciones previas al 
cuadro actual (respiratorias y no respiratorias) en el último año.

$\mathrm{Al}$ ingreso su temperatura era de $37,5^{\circ} \mathrm{C}$, presión arterial de 140/80 $\mathrm{mmHg}$, frecuencia cardiaca de 92 latidos por minuto, 24 respiraciones por minuto, saturación de oxígeno de $100 \%$ con $\mathrm{FIO}_{2}$ de $21 \%$, disminución del murmullo pulmonar y crepitaciones en las bases pulmonares; trofismo y fuerza muscular conservados.

Laboratorio inicial: hemoglobina $13 \mathrm{~g} / \mathrm{dL}$, leucocitos $12.820 / \mathrm{uL}$, plaquetas $223.000 / \mathrm{uL}, \mathrm{CK}$ $62.768 \mathrm{U} / \mathrm{L}$ (valor normal: 55-170 U/l), troponina $0.15 \mathrm{ng} / \mathrm{dL}, \mathrm{LDH} 1.110 \mathrm{UI} / \mathrm{L}$, nitrógeno ureico $36 \mathrm{mg} / \mathrm{dL}$, creatinina $2,1 \mathrm{mg} / \mathrm{dL}$, sodio sérico 132 $\mathrm{mEq} / \mathrm{L}$, potasio sérico $4,3 \mathrm{mEq} / \mathrm{l}$, cloruro sérico $94 \mathrm{mEq} / \mathrm{L}$, GOT $1347 \mathrm{UI} / \mathrm{L}$, dímero D 1,140 ng/ $\mathrm{mL}$, ferritina $1.201 \mathrm{ng} / \mathrm{mL}$, recuento de linfocitos $910 \mathrm{cls} / \mathrm{mm}^{3}$. Análisis de orina: proteínas $30 \mathrm{mg} /$ dL, glucosa (-), leucocitos 0-2 / campo, eritrocitos 5-10 /campo, cilindros (-). ECG con ritmo sinusal, sin alteraciones de conducción ni del ST.

La radiografía simple de tórax mostró opacida- des en el relleno alveolar bilateral y un TC de tórax (Figura 1) compatible con neumonía multifocal, sugiriendo una infección por COVID-19.

Un ensayo complementario con reacción en cadena de la polimerasa para COVID-19 (PCR-COVID 19) fue positivo, mientras que un panel respiratorio de hisopado nasofaríngeo fue negativo para Adenovirus, Coronavirus (229E, HKU1, OC43, NL62), Metapneumovirus, Rinovirus, Influenza A, Influenza H1-H3, Influenza B, Parainfluenza 1-2-3-4, Virus respiratorio sincitial, Bordetella pertussis, Bordetella parapertussis, Chlamydophila pneumoniae y Mycoplasma pneumoniae. Los hemocultivos fueron negativos. Dado el cuadro clínico y la ausencia de elementos en la anamnesis, examen físico y exámenes de laboratorio sugerentes de otras causas de rabdomiolisis, se interpretó el cuadro clínico como rabdomiolisis causada por COVID-19.

El paciente recibió hidratación intravenosa con suero fisiológico al 0,9\%, infusión de bicarbonato de sodio $2 / 3 \mathrm{M}$, Ceftriaxona (2 g/día IV)

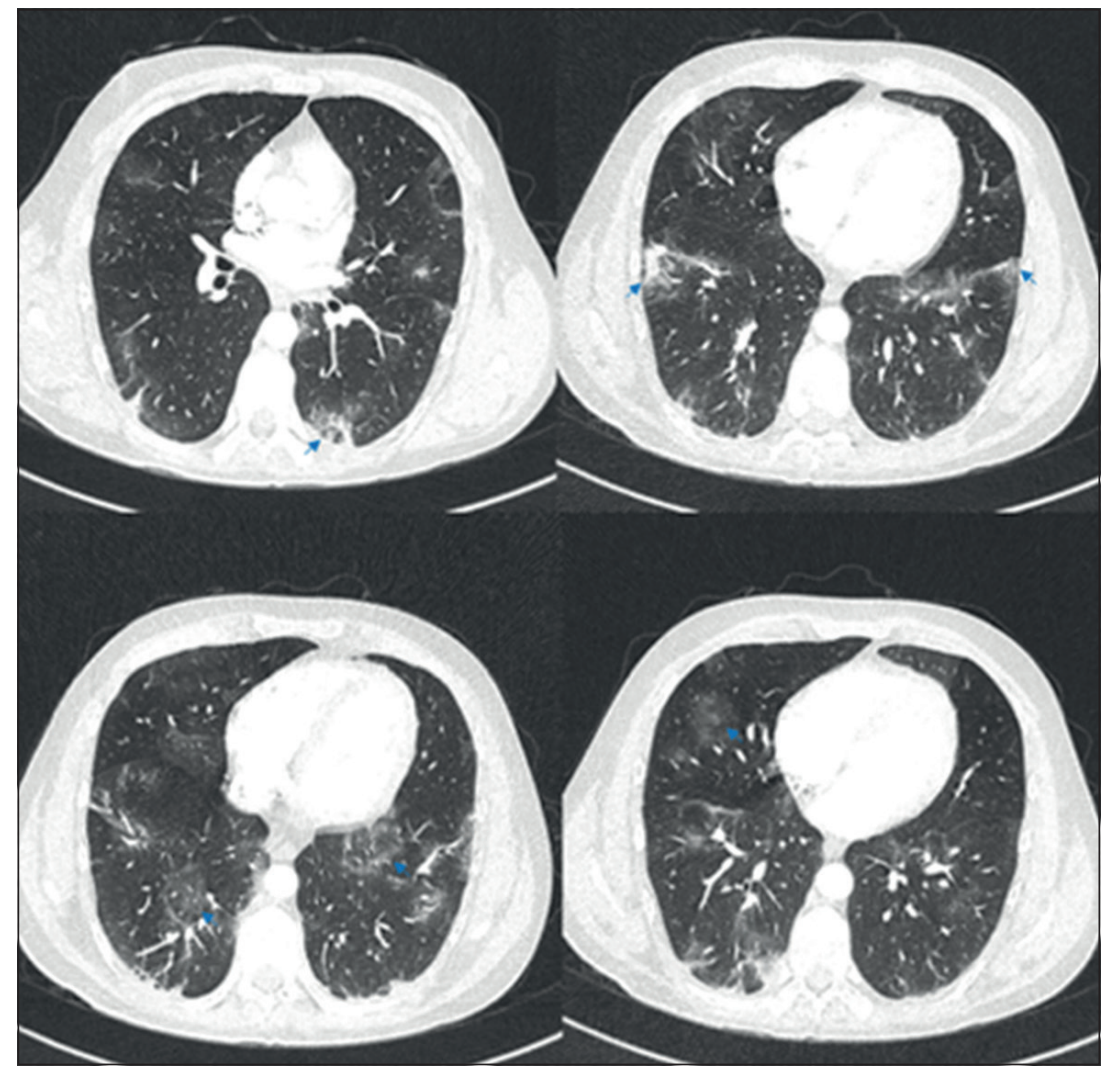

Figura 1. TC de tórax con contraste. Las flechas azules muestran focos periféricos de vidrio esmerilado, algunos de morfología redonda, comprometiendo todos los lóbulos. 
Tabla 1. Exámenes de laboratorio del paciente durante su hospitalización

\begin{tabular}{|c|c|c|c|c|c|c|c|c|c|c|}
\hline $\begin{array}{l}\text { Exámenes de } \\
\text { laboratorio }\end{array}$ & $\begin{array}{c}\text { Día } 0 \\
\text { (ingreso) }\end{array}$ & Día 1 & Día 2 & Día 3 & Día 4 & Día 5 & Día 6 & Día 8 & $\begin{array}{l}\text { Día } \\
10\end{array}$ & $\begin{array}{c}\text { Día } \\
12\end{array}$ \\
\hline Nitrógeno ureico (mg/dL) & 36 & 34 & 48 & 51 & 49 & 41 & 34 & 31 & 29 & 22 \\
\hline Creatinina sérica (mg/dL) & 2,1 & 2,8 & 3,5 & 3,9 & 3,7 & 2,5 & 2,2 & 1,9 & 1,4 & 1,2 \\
\hline Recuento de leucocitos (cls $/ \mathrm{mm}^{3}$ ) & 12.820 & 13.580 & 14.520 & 12.270 & - & 11.580 & - & 9.580 & - & 8.420 \\
\hline Recuento de linfocitos (cls/mm³) & 910 & 876 & 851 & 1.010 & - & 1.250 & - & 1.340 & - & 1.640 \\
\hline $\mathrm{pO}_{2}(\mathrm{mmHg})$ & 76 & 71 & 79 & 75 & - & - & - & - & - & - \\
\hline $\mathrm{pCO}_{2}(\mathrm{mmHg})$ & 32 & 36 & 37 & 38 & - & - & - & - & - & - \\
\hline $\mathrm{PaO}_{2} / \mathrm{FiO}_{2}(\mathrm{mmHg})$ & 360 & 338 & 376 & 357 & - & - & - & - & - & - \\
\hline $\mathrm{SaO}_{2}(\%)^{*}$ & $100 \%$ & $97 \%$ & $99 \%$ & $97 \%$ & $96 \%$ & $95 \%$ & $96 \%$ & $97 \%$ & $97 \%$ & $96 \%$ \\
\hline CK total (U/L) & 62.768 & 72.140 & 50.346 & 23.506 & 8.691 & 1.369 & - & 915 & - & 480 \\
\hline Ferritina $(\mathrm{ng} / \mathrm{mL})$ & 1.201 & - & - & 1.020 & - & - & - & 529 & - & - \\
\hline Dímero D (ng/mL) & 1.140 & - & - & 860 & - & - & - & 314 & - & - \\
\hline
\end{tabular}

$\mathrm{pO}_{2}$ : Presión arterial de oxígeno, $\mathrm{pCO}_{2}$ : Presión arterial de dióxido de carbono, $\mathrm{PaO}_{2} / \mathrm{FiO}_{2}$ : Índice de presión arterial de oxígeno dividido por la fracción de inspiración de oxígeno, $\mathrm{SaO}_{2}$ : Saturación arterial de oxígeno. * $\mathrm{La}^{\mathrm{SaO}_{2}}$ fue medida en gases arteriales hasta el día 3, luego fue medida mediante oximetría de pulso.

y Azitromicina ( $500 \mathrm{mg} /$ día IV), ambos durante 5 días. Desarrolló poliuria ( $4.200 \mathrm{ml} /$ día), junto a un aumento de la creatinina $(3,97 \mathrm{mg} / \mathrm{dL})$ y nitrógeno ureico $(51 \mathrm{mg} / \mathrm{dL})$. La Tabla 1 muestra el detalle de la evolución de los exámenes de laboratorio del paciente. Para el día 5 de tratamiento el paciente presentaba una disminución de CK (1.369 U/L), GOT (411 U/L) y creatinina $(2,5 \mathrm{mg} / \mathrm{dL})$. El paciente fue dado de alta el día 12 con CK (480 U/L) y creatinina $(1,2 \mathrm{mg} / \mathrm{dL})$, con recuperación clínica. No presentó síntomas respiratorios ni requerimientos de oxígeno durante su hospitalización.

\section{Discusión}

La infección asociada a COVID-19 es un problema de salud pública mundial, declarado pandemia por la Organización Mundial de la Salud². Sin embargo, hasta ahora quedan dudas sobre su patogenia, formas clínicas y tratamiento.

La rabdomiólisis es un síndrome que se produce de forma secundaria al daño y la degradación muscular ${ }^{3}$. En una serie de 77 pacientes, las causas más frecuentemente reportadas son alcohol (67\%), trauma (39\%), drogas (15\%) e infecciones $(5 \%)^{4}$.
Las etiologías infecciosas asociadas a rabdomiólisis se han descrito principalmente en la población pediátrica: enterovirus, Epstein-Barr, Citomegalovirus, Adenovirus, Herpes simple, Coxsackie y Varicela, mientras que la injuria renal aguda (AKI) es infrecuente ${ }^{5}$. En pacientes adultos, la rabdomiólisis se ha relacionado con una infección grave por Influenza $\mathrm{A}^{6}$, y especialmente con H1N1 en $2009^{7}$. También se ha reportado rabdomiólisis por COVID-19 (Tabla 2 ), ya sea al inicio o durante el transcurso de la enfermedad ${ }^{4,8,9}$.

La injuria renal aguda por rabdomiólisis está presente en $7-10 \%$ de los $\operatorname{casos}^{10}$ y se ha relacionado con tasas más altas de morbilidad y mortalidad $^{11}$. En 2003, se notificaron 3 casos de AKI por SARS-COV- $1^{12}$ y 1 caso por Coxsackie ${ }^{13}$. En COVID-19, la incidencia de AKI es de 0,5\% de los casos, y también se ha asociado a mayores tasas de morbilidad y mortalidad ${ }^{14}$.

Se han propuesto tres mecanismos para el daño muscular: invasión directa, inducción de citocinas y falla orgánica múltiple ${ }^{14,15}$.

$\mathrm{Al}$ analizar el diagnóstico diferencial de rabdomiólisis, se debe hacer una anamnesis dirigida, preguntando por antecedentes de contusiones, traumas, lesiones musculares (caídas, golpes, 
Tabla 2. Casos reportados de rabdomiolisis por COVID-19

\begin{tabular}{|c|c|c|c|c|}
\hline $\begin{array}{l}\text { Paciente } \\
\text { (Referencia) }\end{array}$ & Signos y Síntomas & Laboratorio & Diagnóstico & Tratamiento \\
\hline $\begin{array}{l}\text { Hombre, } \\
37 \text { años* }\end{array}$ & $\begin{array}{l}\text { Mialgia proximal, náuseas } \\
\text { y epigastralgia por } 3 \text { días. } \\
\text { Temp } 37,5^{\circ} \mathrm{C}, \mathrm{FC} 92 \mathrm{Lpm} \text {, } \\
\mathrm{PA} 140 / 80 \mathrm{mmHg}, \mathrm{FR} 24 \\
\text { Ipm, } \mathrm{SatO}_{2} 100 \% \text { a } \mathrm{FlO}_{2} \\
21 \%\end{array}$ & 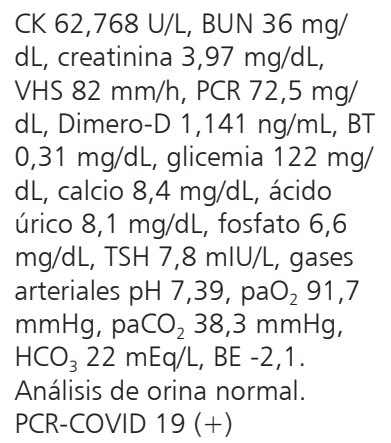 & $\begin{array}{l}\text { Rabdomiólisis } \\
\text { inducida por } \\
\text { COVID-19 } \\
\text { AKI por necrosis } \\
\text { tubular aguda } \\
\text { tóxica inducida } \\
\text { por pigmentos }\end{array}$ & $\begin{array}{l}\text { Solución salina al 0,9\% } \\
\text { IV Bicarbonato de } \\
\text { sodio IV } \\
\text { Ceftriaxona }\end{array}$ \\
\hline $\begin{array}{l}\text { Hombre, } \\
88 \text { años }^{3}\end{array}$ & 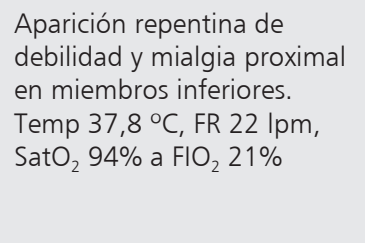 & $\begin{array}{l}\text { CK 13,581 U/L, LDH } 364 \\
\text { U/L, creatinina 1,16 mg/ } \\
\text { dL (valor inicial). Hematuria } \\
\text { microscópica. PCR-COVID-19 } \\
\text { (+). La radiografía de tórax } \\
\text { mostró un leve derrame pleural } \\
\text { izquierdo }\end{array}$ & $\begin{array}{l}\text { Rabdomiólisis } \\
\text { inducida por } \\
\text { COVID-19 }\end{array}$ & $\begin{array}{l}\text { Hidratación intravenosa } \\
\text { Furosemida } \\
\text { Hidroxicloroquina }\end{array}$ \\
\hline $\begin{array}{l}\text { Mujer, } \\
75 \text { años }^{9}\end{array}$ & $\begin{array}{l}\text { Debilidad general y pérdida } \\
\text { de apetito }\end{array}$ & $\begin{array}{l}\text { CK } 2.767 \mathrm{U} / \mathrm{L}, \mathrm{Na} 152 \mathrm{mEq} / \mathrm{L} \text {, } \\
\text { Creatinina 1,2 mg/dL, UN } 31 \\
\mathrm{mg} / \mathrm{dL}, \mathrm{LDH} 497 \mathrm{U} / \mathrm{L}, \mathrm{PCR} 3,7 \\
\mathrm{mg} / \mathrm{dL} \text {, Dímero-D } 573 \mathrm{ng} / \\
\mathrm{mL} \text {, Ferritina } 2.134 \mathrm{ng} / \mathrm{mL} \text {. } \\
\text { Hematuria microscópica. PCR- } \\
\text { COVID-19 (+) }\end{array}$ & $\begin{array}{l}\text { Rabdomiólisis } \\
\text { inducida por } \\
\text { COVID-19 } \\
\text { Enfermedad } \\
\text { coronaria }\end{array}$ & $\begin{array}{l}\text { Hidratación IV } \\
\text { Terapia con oxígeno } \\
\text { Azitromicina } \\
\text { Vancomicina } \\
\text { Cefepime } \\
\text { Aspirina } 324 \mathrm{mg} \\
\text { Atorvastatina } 80 \mathrm{mg} \\
\text { Clopidogrel } 600 \mathrm{mg} \\
\text { Heparina IV } \\
\text { Hidroxicloroquina }\end{array}$ \\
\hline $\begin{array}{l}\text { Hombre, } \\
71 \text { años }^{9}\end{array}$ & $\begin{array}{l}\text { Dolor en miembros } \\
\text { inferiores y debilidad } \\
\text { generalizada. Afebril y sin } \\
\text { alteraciones hemodinámicas }\end{array}$ & $\begin{array}{l}\text { CK } 1.859 \mathrm{U} / \mathrm{L}, \mathrm{UN} 78 \mathrm{mg} / \mathrm{dL} \text {, } \\
\text { Creatinina 3,6 mg/dL } \\
\text { (valor inicial), LDH } 538 \mathrm{U} / \mathrm{L} \text {, } \\
\text { Dímero-D } 989 \mathrm{ng} / \mathrm{mL} \text {, } \\
\text { Ferritina } 1.003 \mathrm{ng} / \mathrm{mL}, \mathrm{PCR} \\
18,8 \mathrm{mg} / \mathrm{dL} . \text { Hematuria } \\
\text { microscópica. } \\
\text { PCR-COVID-19 (+) }\end{array}$ & $\begin{array}{l}\text { Rabdomiólisis } \\
\text { inducida por } \\
\text { COVID-19 } \\
\text { Enfermedad } \\
\text { renal crónica. } \\
\text { Fibrilación } \\
\text { auricular }\end{array}$ & $\begin{array}{l}\text { Hidratación IV } \\
\text { Terapia con oxígeno } \\
\text { Doxiciclina } \\
\text { Ceftriaxona } \\
\text { Hidroxicloroquina } \\
\text { Metoprolol } \\
\text { Heparina IV }\end{array}$ \\
\hline $\begin{array}{l}\text { Hombre, } \\
60 \text { años }^{8}\end{array}$ & $\begin{array}{l}\text { Temp } 38,3^{\circ} \mathrm{C} \text { durante } 3 \\
\text { días. FC } 89 \text { Ipm, PA } 135 / 91 \\
\text { mmHg, FR } 18 \mathrm{lpm}, \mathrm{SatO}_{2} \\
93 \% \text { a } \mathrm{FIO}_{2} 21 \%\end{array}$ & $\begin{array}{l}\text { Leucocitos 3.310, LDH } \\
2.137 \mathrm{U} / \mathrm{L}, \mathrm{PCR} 111 \mathrm{mg} / \mathrm{L} \text {, } \\
\text { CK } 17.434 \mathrm{U} / \mathrm{L} \text { (normal al } \\
\text { ingreso), creatinina 0,78 mg/ } \\
\text { dL, hematuria microscópica. } \\
\text { PCR-COVID-19 (+) }\end{array}$ & $\begin{array}{l}\text { Rabdomiólisis } \\
\text { inducida por } \\
\text { COVID-19 }\end{array}$ & $\begin{array}{l}\text { Hidratación IV } \\
\text { Terapia con oxígeno } \\
\text { Bicarbonato de sodio IV } \\
\text { Meropenem } \\
\text { Metilprednisolona } \\
\text { Transfusión de plasma } \\
\text { Gammaglobulina }\end{array}$ \\
\hline $\begin{array}{l}\text { Hombre, } \\
71 \text { años }^{16}\end{array}$ & $\begin{array}{l}1 \text { semana de tos seca, } \\
\text { disnea y fiebre } 38^{\circ} \mathrm{C} \text {, con } \\
\text { mialgia y artralgia, PA } \\
120 / 68 \mathrm{mmHg}, \mathrm{FC} 90 \mathrm{lpm} \text {, } \\
\mathrm{FR} 22 \mathrm{lpm}, \mathrm{SatO}_{2} 84 \% \text { a } \\
\mathrm{FIO}_{2} 21 \%\end{array}$ & $\begin{array}{l}\text { Creatinina } 1,68 \mathrm{mg} / \mathrm{dL}, \mathrm{CK} \\
8.720 \mathrm{U} / \mathrm{L} \text {, mioglobina } 2.079 \\
\text { ng/mL, Ferritina } 2.603 \mathrm{ng} / \mathrm{mL} \text {. } \\
\text { PCR-COVID-19 (+). } \\
\text { TC tórax con infiltrados } \\
\text { bilaterales con áreas de } \\
\text { consolidación y amplias } \\
\text { opacidades en vidrio } \\
\text { esmerilado }\end{array}$ & $\begin{array}{l}\text { Rabdomiólisis } \\
\text { inducida por } \\
\text { COVID-19 }\end{array}$ & $\begin{array}{l}\text { Hidratación IV } \\
\text { Terapia con oxígeno } \\
\text { Bicarbonato de sodio IV } \\
\text { Azitromicina } \\
\text { Ceftriaxona } \\
\text { Hidroxicloroquina } \\
\text { Lopinavir/ritonavir } \\
\text { Tocilizumab }\end{array}$ \\
\hline
\end{tabular}




\begin{tabular}{|c|c|c|c|c|}
\hline $\begin{array}{l}\text { Hombre, } \\
38 \text { años }^{17}\end{array}$ & $\begin{array}{l}1 \text { semana de fiebre, mialgia, } \\
\text { náuseas, vómitos, tos seca, } \\
\text { disnea y dolor abdominal. } \\
\mathrm{SatO}_{2} 91 \% \text { a } \mathrm{FIO}_{2} 21 \%\end{array}$ & $\begin{array}{l}\text { Mioglobina (normal al ingreso) } \\
21.000 \mathrm{ng} / \mathrm{m} \text {, Creatinina } \\
\text { (normal al ingreso) 4,7 mg/dL, } \\
\text { PCR mg/L. PCR-COVID-19 (+). } \\
\text { TC con extensa opacidades en } \\
\text { vidrio esmerilado }\end{array}$ & $\begin{array}{l}\text { Miositis } \\
\text { inducida por } \\
\text { COVID-19 con } \\
\text { rabdomiolisis } \\
\text { grave y AKI }\end{array}$ & $\begin{array}{l}\text { Hidratación IV } \\
\text { Terapia con oxígeno } \\
\text { Cefotaxima } \\
\text { Albúmina, furosemida, } \\
\text { espironolactona y } \\
\text { manitol } \\
\text { Diálisis }\end{array}$ \\
\hline $\begin{array}{l}\text { Hombre, } \\
78 \text { años }^{18}\end{array}$ & $\begin{array}{l}\text { Astenia, fiebre } 38^{\circ} \mathrm{C} \text {, } \\
\text { mialgia, debilidad muscular, } \\
\text { con coloración oscura } \\
\text { orina en las últimas } 48 \mathrm{~h} \\
\mathrm{FR} 18 \mathrm{lpm} \text {, SatO } 296 \% \text { a } \\
\mathrm{FIO}_{2} 21 \%\end{array}$ & $\begin{array}{l}\text { CK } 22511 \text { U/L, Dímero-D } \\
1.400 \mathrm{ng} / \mathrm{mL}, \mathrm{PCR} 131 \\
\mathrm{mg} / \mathrm{L} \text {, creatinina } 3,2 \mathrm{mg} / \mathrm{dL} \text {, } \\
\text { Mioglobinuria }(+) \\
\text { PCR-COVID-19 (+) }\end{array}$ & $\begin{array}{l}\text { Rabdomiólisis } \\
\text { inducida por } \\
\text { COVID-19. } \\
\text { AKI }\end{array}$ & $\begin{array}{l}\text { Hidratación IV } \\
\text { Hidroxicloroquina } \\
\text { Lopinavir/ritonavir }\end{array}$ \\
\hline $\begin{array}{l}\text { Hombre, } \\
19 \text { años }^{19}\end{array}$ & $\begin{array}{l}\text { Mialgias, orinas color rojo y } \\
\text { tos seca de } 3 \text { días }\end{array}$ & $\begin{array}{l}\text { Leucopenia } 2.400 \text { con lin- } \\
\text { fopenia, CK } 284.240 \mathrm{U} / \mathrm{L} \text {, GOT } \\
1.014 \mathrm{U} / \mathrm{L}, \mathrm{GPT} 132 \mathrm{U} / \mathrm{L} \text {, hema- } \\
\text { turia }(+) \text {, PCR-COVID } 19(+)\end{array}$ & $\begin{array}{l}\text { Rabdomiólisis } \\
\text { inducida por } \\
\text { COVID-19 }\end{array}$ & Hidratación IV \\
\hline $\begin{array}{l}\text { Hombre, } \\
16 \text { años }^{20}\end{array}$ & $\begin{array}{l}\text { Fiebre, mialgia, disnea y } \\
\text { orina de color oscuro de } \\
4 \text { días, temp } 38,9^{\circ} \mathrm{C}, \mathrm{PA} \\
133 / 87 \mathrm{mmHg}, \mathrm{FC} 122 \mathrm{lpm}, \\
\mathrm{FR} 20 \mathrm{lpm}, \mathrm{SatO}_{2} 99 \% \text { a } \\
\mathrm{FIO}_{2} 21 \%\end{array}$ & $\begin{array}{l}\text { CK } 427,656 \text { U/L, GOT } 839 \text { U/L, } \\
\text { GPT } 157 \text { U/L. Análisis de orina: } \\
11-25 \text { GR y } 6-10 \text { GB. PCR- } \\
\text { COVID-19 (+) }\end{array}$ & $\begin{array}{l}\text { Rabdomiólisis } \\
\text { inducida por } \\
\text { COVID-19 }\end{array}$ & $\begin{array}{l}\text { Hidratación IV } \\
\text { Acetaminofén } \\
\text { Morfina } \\
\text { Amlodipino } 5 \text { mg }\end{array}$ \\
\hline $\begin{array}{l}\text { Hombre, } \\
60 \text { años }^{21}\end{array}$ & $\begin{array}{l}\text { Mialgias y fatiga de } 2 \text { días. } \\
\text { PA } 120 / 70 \mathrm{mmHg}, \mathrm{FR} 18 \\
\mathrm{lpm}, \mathrm{FC} 93 \mathrm{lpm} \text {, temp } \\
36,7^{\circ} \mathrm{C} \text {, SatO } 28 \% \text { a } \mathrm{FIO}_{2} \\
21 \%\end{array}$ & $\begin{array}{l}\text { CK 4,267 U/L, PCR 35,1 mg/L, } \\
\text { Dímero-D, } 210 \mathrm{ng} / \mathrm{mL}, \mathrm{LDH} \\
575 \text { U/L, ferritin } 428 \mathrm{ng} / \mathrm{mL} \text {. } \\
\text { PCR-COVID-19 (+) }\end{array}$ & $\begin{array}{l}\text { Rabdomiólisis } \\
\text { inducida por } \\
\text { COVID-19 }\end{array}$ & $\begin{array}{l}\text { Hidratación IV } \\
\text { Bicarbonato de sodio IV } \\
\text { Hidroxicloroquina } \\
\text { Oseltamivir } \\
\text { Azitromicina } \\
\text { Favipiravir }\end{array}$ \\
\hline $\begin{array}{l}\text { Hombre, } \\
46 \text { años }^{22}\end{array}$ & $\begin{array}{l}\text { Tos, fiebre, disnea y dolor } \\
\text { muscular generalizado por } \\
5 \text { días }\end{array}$ & $\begin{array}{l}\text { Creatinina de } 11 \mathrm{mg} / \\
\mathrm{dL}, \mathrm{CK}>400.000 \mathrm{U} / \mathrm{L} \text {. } \\
\text { Hemoglobinuria (+). Rx tórax } \\
\text { con vidrio esmerilado bilateral y } \\
\text { difuso. PCR-COVID-19 }(+)\end{array}$ & $\begin{array}{l}\text { Rabdomiólisis } \\
\text { inducida por } \\
\text { COVID-19. } \\
\text { AKI }\end{array}$ & $\begin{array}{l}\text { Hidratación IV } \\
\text { Bicarbonato de sodio IV } \\
\text { Terapia con oxígeno } \\
\text { Diálisis } \\
\text { Azitromicina }\end{array}$ \\
\hline $\begin{array}{l}\text { Hombre, } \\
67 \text { años }^{23}\end{array}$ & $\begin{array}{l}\text { Fiebre y disnea, } \mathrm{SatO}_{2} 80 \% \\
\mathrm{a} \mathrm{FlO}_{2} 21 \%\end{array}$ & $\begin{array}{l}\text { CK } 589 \mathrm{U} / \mathrm{L} \text {, creatinina 1,16 } \\
\mathrm{mg} / \mathrm{dL}, \mathrm{PCR} 157,9 \mathrm{mg} / \mathrm{L} \text {. TC } \\
\text { tórax con opacidad en vidrio } \\
\text { esmerilado. PCR-COVID-19 (+) }\end{array}$ & $\begin{array}{l}\text { Rabdomiólisis } \\
\text { inducida por } \\
\text { COVID-19. } \\
\text { AKI }\end{array}$ & $\begin{array}{l}\text { Hidratación IV } \\
\text { Terapia con oxígeno } \\
\text { Azitromicina } \\
\text { Ceftriaxona } \\
\text { Hidroxicloroquina }\end{array}$ \\
\hline $\begin{array}{l}\text { Hombre, } \\
39 \text { años }^{23}\end{array}$ & $\begin{array}{l}\text { Fiebre, mialgia, disnea y } \\
\text { estado mental alterado }\end{array}$ & $\begin{array}{l}\text { CK } 4.330 \mathrm{U} / \mathrm{L} \text {, creatinina } \\
3,8 \mathrm{mg} / \mathrm{dL}, \mathrm{PCR} 85,5 \mathrm{mg} / \mathrm{L} \text {, } \\
\text { Hematuria (+). Rx de tórax con } \\
\text { infiltrado pulmonar bilateral. } \\
\text { PCR-COVID-19 (+) }\end{array}$ & $\begin{array}{l}\text { Rabdomiólisis } \\
\text { inducida por } \\
\text { COVID-19 }\end{array}$ & Falleció el $1^{\text {er }}$ día \\
\hline $\begin{array}{l}\text { Hombre, } \\
43 \text { años }^{23}\end{array}$ & $\begin{array}{l}\text { Tos, disnea, mialgias, fiebre } \\
\text { de } 2 \text { días. } \mathrm{FC} 107 \mathrm{lpm}, \mathrm{PA} \\
94 / 61 \mathrm{mmHg} \text {, temp } 37,1^{\circ} \mathrm{C} \text {, } \\
\mathrm{SatO}_{2} 99 \% \text { a } \mathrm{FlO}_{2} 21 \%\end{array}$ & $\begin{array}{l}\text { CK } 8.636 \text { U/L, creatinina } \\
20 \text { mg/dL, PCR } 249 \text { mg/L. } \\
\text { PCR-COVID-19 (+) }\end{array}$ & $\begin{array}{l}\text { Rabdomiólisis } \\
\text { inducida por } \\
\text { COVID-19 }\end{array}$ & $\begin{array}{l}\text { Ceftriaxona } \\
\text { Hidroxicloroquina } \\
\text { Azitromicina } \\
\text { Falleció el } 2^{\text {do }} \text { día }\end{array}$ \\
\hline $\begin{array}{l}\text { Hombre, } \\
70 \text { años }^{23}\end{array}$ & $\begin{array}{l}\text { Disnea y tos de } 8 \text { días. } \\
\mathrm{FC} 101 \mathrm{lpm}, \mathrm{PA} 94 / 61 \\
\mathrm{mmHg}, \mathrm{FR} 20 \mathrm{lpm} \text {, temp } \\
37,2^{\circ} \mathrm{C}, \mathrm{SatO}_{2} 87 \% \text { a } \mathrm{FIO}_{2} \\
21 \%\end{array}$ & $\begin{array}{l}\text { CK } 5.008 \mathrm{U} / \mathrm{L} \text {, creatinina } \\
1,68 \mathrm{mg} / \mathrm{dL}, \mathrm{PCR} 363,3 \mathrm{mg} / \mathrm{L} \text {, } \\
\text { Hematuria (+). Rx de tórax con } \\
\text { infiltrado pulmonar bilateral } \\
\text { PCR-COVID-19 (+) }\end{array}$ & $\begin{array}{l}\text { Rabdomiólisis } \\
\text { inducida por } \\
\text { COVID-19 }\end{array}$ & $\begin{array}{l}\text { Hidratación IV } \\
\text { Terapia con oxígeno } \\
\text { Metilprednisolona } \\
40 \text { mg ceftriaxona }\end{array}$ \\
\hline
\end{tabular}

*Reporte de caso, CK: Creatina quinasa, FC: Frecuencia cardíaca, $\mathrm{FIO}_{2}$ : Fracción de oxígeno inspirado, FR: Frecuencia respiratoria, IV: Intravenoso, Lpm: Latidos por minuto, BUN: Nitrógeno ureico, PA: Presión arterial, PCR: Proteína C reactiva, BT: Bilirrubina total, PCR-COVID-19: Reacción de polimerasa en cadena para COVID-19, SatO 2 : saturación de oxígeno, Temp: Temperatura, GR: Glóbulos rojos, GB: Glóbulos blancos. 
accidentes de tránsito o en domicilio), ejercicio extenuante o prolongado, especialmente si el paciente no presenta un entrenamiento físico apropiado previo. También debe incluir antecedentes de uso de medicamentos que pudieran tener efectos musculares (especialmente estatinas o colchicina), uso de drogas (incluyendo cocaína, heroína, anfetaminas, LSD, hongos, entre otros), picaduras de insectos o arañas y mordedura de animales venenosos. Junto con esto, deben evaluarse la presencia de infecciones recientes, dirigida a cuadros causados por los virus y bacterias anteriormente señalados. Finalmente deben excluirse las miopatías inflamatorias secundarias a toxinas o inmunomediadas ${ }^{12}$. Dado que ninguna otra causa podría explicar el daño muscular y el paciente se recuperó de la infección, concluimos que la rabdomiólisis fue secundaria a COVID-19.

El tratamiento de la rabdomiolisis tiene 3 etapas: a) Identificación y corrección de la causa, cuando es posible (ejemplo, suspensión de estatinas); b) Corrección de la depleción de volumen; c) Medidas de prevención de formación de depósitos renales de pigmentos (responsables del daño renal). La medida inicial es la administración de cristaloides en forma precoz y agresiva, alrededor de 500-1.000 L por hora en las primeras horas, disminuyendo progresivamente el aporte. Se considera que el paciente tiene mayor riesgo de AKI con niveles de CK total mayores a 5.000 U/L. En estos pacientes, se recomienda el uso de bicarbonato de sodio endovenoso para prevenir depósitos renales de pigmentos. Se puede iniciar a 1-2 $\mathrm{mEq} / \mathrm{L} / \mathrm{hr}$ con la meta de $\mathrm{pH}$ urinario mayor a 6,5 , con ajuste progresivo del aporte endovenoso. En casos severos con compromiso renal, se puede iniciar hemodiálisis, según las indicaciones habituales de diálisis de urgencia. No se ha demostrado que la terapia de reemplazo renal sea eficaz para la remoción de los pigmentos, por lo que no se recomienda de rutina.

Cabe señalar que, en el caso presentado, pese a las alteraciones musculares y renales, no hubo compromiso respiratorio clínicamente significativo, aun existiendo compromiso pulmonar identificado mediante imágenes. Esto también se ha observado en varios casos reportados en la literatura (Tabla 2). Estos datos sugieren que el cuadro clínico del paciente con rabdomiolisis causada por COVID-19 podría implicar un perfil diferente de la enfermedad.
Si bien esta es una forma poco común, debemos tener en cuenta que aún se desconoce la gama completa de manifestaciones de la enfermedad y se requieren estudios científicos básicos para aclarar su patogénesis.

Por tanto, concluimos que la rabdomiólisis asociada a COVID-19 es una manifestación rara con complicaciones potencialmente letales. Se debe instar a los médicos a considerar explorar el compromiso muscular en la evaluación inicial, de modo que se pueda obtener un diagnóstico y tratamiento tempranos, como se hizo en este caso.

\section{Referencias}

1. Alijotas-Reig J, Esteve-Valverder E, Belizna C. Immunomodulatory therapy for the management of severe COVID-19- Beyond the anti-viral therapy: A comprehensive review. Autoimmunity Reviews. 2020; 12: 102555.

2. Ge H, Wang X, Yuan X, Xiao G, Wang C, Deng T. The epidemiology and clinical information about COVID-19. Eur J Clin Microbiol Infect Dis. 2020; 4 (14): 1-9. [PMID: 32291542].

3. Suwanwongse K, Shabarek N. Rabdomyolysis as a presentation of 2019 Novel Coronavirus Disease. Cureus. 2020; Apr 6; 12 (4): e7561. [PMID: 32382463].

4. Gabow PA, Kaehny WD, Kelleher SP. The spectrum of rhabdomyolysis. Medicine 1982; 61 (3): 141-52. [PMID: 7078398].

5. Mannix R, Tan ML, Wright R, Baskin M. Acute pediatric rhabdomyolysis: cause and rates of renal failure. Pediatrics. 2006; 118: 2119-25. [PMID: 17079586].

6. Ibrahim A, Manthri S, Soriano P. Rhabdomyolisis associated with Influenza A virus infection. Cureus. 2018; 10 (6): e2786. [PMID: 30112262].

7. Fadila M, Wool K. Rhabdomyolysis secondary to Influenza A infection: A case report and review of literature. North Am J Med Sci. 2015; 7: 122-4. [PMID: 25839005].

8. Jin M, Tong Q. Rhabdomyolysis as potential late complication associated with COVID-19. Emerging Infectious Disease. 2020; 26 (7). [PMID: 32197060].

9. Chan K, Farouji I, Hanoud A, Slim J. Weakness and elevated creatinine kinase as the initial presentation of COVID-19. American Journal of Emergency Medicine 2020; 26 (7). [PMID: 32414522].

10. Bosch X, Poch E, Grau JM. Rhabdomyolysis and Acute Kidney Injury. N Engl J Med. 2009; 361 (1): 62-72. [PMID: 19571284]. 
11. Safari S, Yousefifard M, Hashemi B, Baratloo A, Forouzanfar MM, Rahmati F, et al. The value of serum creatine kinase in predicting the risk of rhabdomyolysis-induced acute kidney injury: a systematic review and meta-analysis. Clin Exp Nephrol. 2016; 20 (2): 153-61. [PMID: 26801932].

12. Chen L, Hsu C, Tian Y, Fang J. Rhabdomyolysis associated with acute renal failure in patients with severe acute respiratory syndrome. Int J Clin Pract. 2005; 59 (10): 1162-6. [PMID: 16178983].

13. Fodili F, Van Bommel E. Severe rhabdomyolysis and acute renal failure following recent Coxsackie B virus infection. The Journal of Medicine. 2003; 61 (5): 177-9. [PMID: 12916546].

14. Ronco C, Reis T. Kidney involvement in COVID-19 and rationale for extracorporeal therapies. Nature Neph. 2020; 16: 308-10. [PMID: 32273593].

15. Fadila MF, Wool KJ. Rhabdomyolysis secondary to influenza infection: A case report and review of the literature. N Am K Med Sci. 2015; 7 (3): 122-4. [PMID: 25839005].

16. Valente-Acosta B, Moreno-Sanchez F, Fueyo-Rodriguez $\mathrm{O}$, Palomar-Lever A. Rhabdomyolysis as an initial presentation in a patient diagnosed with COVID-19. BMJ Case Rep. 2020; 13 (6) [PMID: 32587121].

17. Taxbro K, Kahlow H, Wulcan H, Fornarve A. Rhabdomyolysis and acute kidney injury in severe COVID-19 in- fection. BMJ Case Rep. 2020; 13 (9) [PMID: 32878841].

18. Rivas-García S, Bernal J, Bachiller-Corral J. Rhabdomyolysis as the main manifestation of coronavirus disease 2019. Rheumatology (Oxford). 2020; 59 (8): 2174-6. [PMID: 32584414].

19. Shanbhag A, Manaktala PS, Rizvi H, Frey K, Narayanan R. COVID-19 Presenting as Severe Rhabdomyolysis With Normal Renal Function. Cureus. 2020; 12 (8) [PMID: 32905464].

20. Gefen AM, Palumbo N, Nathan SK, Singer PS, Castellanos-Reyes LJ, Sethna CB. Pediatric COVID-19-associated rhabdomyolysis: a case report. Pediatr Nephrol. 2020; 35 (8): 1517-20. [PMID: 32447505].

21. Borku Uysal B, Ikitimur H, Yavuzer S, Islamoglu MS, Cengiz M. Case Report: A COVID-19 Patient Presenting with Mild Rhabdomyolysis. Am J Trop Med Hyg. 2020; 103 (2): 847-50. doi: 10.4269/ajtmh.20-0583. Epub 2020 Jun 19. [PMID: 32563271].

22. Solís JG, Esquivel Pineda A, Alberti Minutti P, Albarrán Sánchez A. Case Report: Rhabdomyolysis in a Patient with COVID-19: A Proposed Diagnostic-Therapeutic Algorithm. Am J Trop Med Hyg. 2020; 103 (3): 1158-61. doi: 10.4269/ajtmh.20-0692. [PMID: 32729460].

23. Singh B, Kaur P, Mechineni A, Maroules M. Rhabdomyolysis in COVID-19: Report of Four Cases. Cureus. 2020; 12 (9): e10686. doi: 10.7759/cureus.10686. [PMID: 33005556]. 